\title{
DEFINING STRATEGY USING VISION AND MISSION STATEMENTS OF CROATIAN ORGANIZATIONS IN TIMES OF CRISIS
}

\author{
Ana Čuić Tankovića \\ ${ }^{a}$ M.Econ., M.Music; Phd student, Assistant at Faculty of management of tourism and hospitality, Opatija, University of \\ Rijeka
}

\section{ARTICLE INFO}

Keywords:

- Strategy

- Turbulent Environments

- Vision statement

- Mission statement

\section{ABSTRACT}

The basic subjects of this paper are the mission and vision statements as well as their connection with the definition of strategy.

New approaches to strategy development and implementation studies analyse the possibilities of adapting strategies to turbulent environments constantly changing the definition of strategy. Organizations proclaim the intention of business through its vision, mission and goals: that is why vision and mission statements are the starting points of any attempt of finding a new definition of strategy. Vision and mission statements of the most successful Croatian organizations in the year 2011 were analysed using core analysis. After finding and ranking the most frequent terms, a new definition of strategy used by Croatian organizations in time of crisis was presented.

Reference to this paper should be made as follows: Čuić Tanković A, . 2013. Defining strategy using vision and mission statements of croatian organizations in times of crisis, Ekonomska istraživanja Economic Research Special Issue 2013 


\section{INTRODUCTION}

The recent years economic uncertainty has acknowledged to managers the importance of readiness to change and improve the strategy, constantly monitoring and controlling the internal and external forces, learning to adapt to new economic challenges, especially in times of crisis.

Mission and vision are an important part not only of strategic management but also of a part of communication with the market because the companies present their organizational intentions to the stakeholders. It is a widely accepted routine that the building of the strategic efforts of an organization begins with market and resource analysis, followed by the mission and vision statement customization in order to subsequently define the strategy itself. Since the strategy is designed and formed according to the organizational needs, the particularities in vision and mission defining during the period of crisis are sought.

Influenced by the modern management, new external variables and especially the global economic crisis, a new approach to strategy formulation was needed. Term crisis management (Shrivastava et al., 1988) was created during 1980's when different industrial and natural disasters took place. These uncertain conditions influenced the decision making process. In terms of an organization, a crisis may be defined as "an assembly of tensional phenomena that leads to a sudden and significant change" and "situation of acute functional perturbation" (Lesenciuc i Nagy, 2008). Crisis management must respond to the situation that occurred. The term "crisis" can be seen as: (1) a threat to the organization, (2) a surprising factor and (3) a short decision making time. In such conditions, crisis management identifies, understands, evaluates and gives solution. According to Lesenciuc i Nagy (2008:104) crisis is considered to be "a factor able of inducing incapacity of decision and the functioning of the organization being either questioned or compromised". Crisis is a new factor that strategy must adapt to, with special consideration to its continuity, formulation, implementation and original mission and vision.

After this introduction, the second part presents the importance of mission and vision statements, meanwhile the third part specially emphasizes the strategy definition and its change during time itself as well as in different periods of time.

The fourth part therefore presents the interest and the methodology of the research, while the fifth part brings in the results and conclusions. The final part analyses the limitations of the conducted research and presents possible guidelines for further research.

\section{THE IMPORTANCE OF MISSION AND VISION STATEMENTS}

The strategic management planning process begins with the environment and resources analysis and proceeds with defining the organization's vision and mission. The statements of the organization are set drawing onto these two elements and they direct complete organization's action.

Vision presents an organization's desired future state projection and the mission explains the purpose and the reason of the organization's present existence. Vision and mission are connected and intertwined. Vision offers the guidelines for development stimulation and gives the business core. According to Collins and Porras (Buble et al. 2005:86), vision has two key components: a base ideology and visionary future. Base ideology gives the reasons of organization existence, its persistent features and authentic identity. Visionary future primarily describes the state of the organization 10 and 30 years from now. It requires predictions that overcome current conditions and resources. It has to be challenging as well as stimulating for the organization itself because all future activity is based on it. 
Mission describes the organization's identity, product, market and the particular methodology or technology of emphasis. The mission statement incorporates specifics about the organization that make it unique and describes "the organization's achievement hopes, such as the size of the organization, the scope of endeavor and the number and diversity of the organization's businesses, markets and customers" (Alkhafaji, 2003). Mission usually reflects the values and priorities of strategic decisions and outlines the vision and future organization's direction. The mission statement goal is ensuring the planned behavior by following the mission guidelines as well as explaining the purpose of existence and the business as a whole to intern and extern stakeholders. According to Lynch (2006), mission statement should be market oriented, real, clear, enforceable, motivating, specific, flexible enough and environment adaptable. From the customer's point of view, the mission statement ensures the frame of his expectations. For the employee, it is the impulse to understand that the decisions the management makes are good.

There are no books on management that do not devote a few paragraphs to the importance of a mission and vision statements for an organization. Vision and mission statements have been recognized as tools of strategic importance. According to Verna (2010), the content of these statements is important because of its influence on people's behavior and resource allocation. Literature on vision and mission statements (Stemler and Bebell, 1999; Mullane, 2002; Morphey and Hartley, 2006; Fox, 2006; Verna, 2010) demonstrates the value of vision and guiding principles: they help forming employee relationships between each other from the inside and the public and the stakeholders, especially with the customers from the outside.

Mission and vision statements are closely connected with the corporation's management strategy perceived as the leading tool in strategic planning. Since the mission and vision are firstly defined and the strategy, often kept as the secret of trade, supervenes from them, mission and vision statement allows choosing the main guidelines of strategy selection. Mullane (2002) perceives two distinct situations in existing organizations - one firm attempts to implement values from a current mission statement in order to define the behavior throughout the organization and the other firm creates a new mission statement and thus defines the values it desires to have in future. The cited paper's author concludes that after the detailed interview with the presidents, mission statements are valuable for the firm's performance when used properly. In both cases, management's first task is the identification of key concepts which can be presented using the key words.

\section{DEFINING STRATEGY}

Mission and vision statement presents a starting point of creating the strategy. The word "strategy" is derived for the Greek word "stratēgos" which literally means "leading an army" (stratos: army, agon: leading, strategos: army leader). After the Romans conquered the Greeks, the word strategia was used by the Roman emperor, the highest leader. In medieval times the word "stratagem" meant the second attempt of defeating the enemy. In $18^{\text {th }}$ century Napoleon's army knew that strategy was crucial to successful victory in every battle and usage of the opponent's resources. Chinese general Sun Tsu in his book "The Art of War" defines the strategy as not only avoiding battles but also fighting them. Military thinking (Macmillan, Tampoe, 2000) has certainly some relevance to business strategy. It emphasizes winning, the importance of leadership and taking action in order to achieve desired results. Strategy has also a political role: In his book "The Prince" Machiavelli moved beyond the ancient writers in his concern for effectiveness as much as describing ideals.

Modern thinking on business strategy firstly evolved into a recognizable form in 1960s in the USA. Defining the present day strategy is one of the greatest challenges of the strategic man- 
agement. The literature about strategy has become so diverse and vast and any review would not be able to cover all perspectives, views and positions. There is not a unique definition of strategy. Different researchers as Chandler (1962), Learned et al. (1965), Mintzberg (1987), Penrose (1993), Sandler i Craig (2003), Lynch (2006) and Huff et al. (2009) tried to explain the concept of strategy in their own time. They presented the image of markets and economy trends in which the strategy is created. The term "strategy" includes different organization's activities and orientations which change and develop together with the business activity: the strategy adapts to new situations on the market. We can define organization's strategy according to its action and decision because „strategy can be formally expressed or silent but still observable by actions and decisions the organization makes" (Hatten 1982:89). Various researchers gave different and interesting definitions of strategy, but what is relevant for the research of this paper are similar terms in the definition. Sandler and Craig (2003) considered it very difficult to find the definition of strategy which can unify all definitions presented by previous authors, so they defined the elements/keywords every strategy definition must contain: purpose or mission; polities; defining the business the company is in; defining the kind of company; objective or goals; strengths and weaknesses; opportunities and threats; key success factors; key decision; capabilities and competences; planning and scheduling; implementation and sustainable competitive advantage.

Huff et al. (2009) identified strategy characteristics important for the organization and summarized them as follows:

Communication of compelling purpose or vision to all in the organization and outside it who want to know it;

Connection between organization's strength and market's opportunities;

Generating more resources than it requires;

Coordinating activities directed to reasonable and submitted achieving success

Capability to adapt and react in new market conditions

Their understanding of strategy definition explains "the desired goals and information on what to do, who will do it, how it will be done, and finally for whom and why the outcomes are valuable" (Huff et al., 2009:6).

The uniform strategy definition that would satisfy theoretical and practical approaches will never be found because the term "strategy" covers different activities and organization goals which develop alongside the business processes continually adapting to new market situations.

The mission and vision statements can mirror the business situation especially in times of crisis and can use the vision and mission statements to define strategy as well as to predict the future organization's actions.

This is why the aim of this paper is to examine the vision and mission statement of the most successful companies in Croatia in the year 2011, try to analyze the words they use, unify the elements of their definitions, create a new concept of defining strategy which will present the picture of strategic management during the economic crisis in Croatia. 


\section{METHOD AND RESEARCH}

The literature research on this topic according to Chun and Davies (2000) suggest that the majority of the works used the most successful company model, as in Fortune 500 or Business Week 1000 .

Similarly the starting point of this research was the list of 400 most successful Croatian organizations in year 2010, published by the newspaper "Privredni vjesnik" in July 2011 (available on http://www.privredni.hr/400-najvecih, March 2013). A random selection was made from the best 100 , resulting in 50 organizations that were analyzed for their public vision and mission statements made, available on their web sites. Since the first work analysing the mission statement by Pearce and David dates from 1987, the data about the mission was being obtained by firstly sending the inquiries about it to the top management, then the accent is laid on the importance of the mission and vision statement availability in order to enable the organization to properly communicate its strategic intentions to the market and to create its e-reputation in accordance with its e-image construction.

That is why the method of content analysis was chosen for this research. It is an appropriate method when the observed phenomenon is communication: it is defined as the objective, systematic and quantitative description of the manifest content of communication which includes observation and analysis. The unit of analysis may be words, characters, themes or topics. The basic premise of content analysis is to classify words of text into content categories. The findings can be treated and presented in quantitative and qualitative forms. In this study, the research findings are presented in qualitative form which is considered to be appropriate, as the objective of this exploratory study is to provide insights in an area where there is limited knowledge.

Steps in the analysis implementation were the following: firstly the mission and vision statements compilation are available on the selected organizations' pages. Secondly the mission and vision statements transcription minding the grammatical inversion. Thirdly identification of the key words and syntagmas mentioned in mission and vision statements and fourthly the ranking of these words and/or syntagmas.

The organizations can create their own definition of mission and vision without a pattern to define it or a regulatory system for unification, so large number of diverse statements was presented, distinguishing in length, focus, style of writing, and generally, importance on creating vision and mission statements.

We can observe that vision and mission statements possess a wide variety of characteristics, as these examples demonstrate:

\section{HEP (Hrvatska Elektroprivreda-Croatian Power Utility)}

Mission: "Safe and high-quality energy supply, with a high degree of social responsibility."

Vision: "Croatian energy leader, with a growing share in the regional market, in production, supply and trading of electricity, which provides a safe and quality service based on the principles of environmentally friendly production, energy efficiency and sustainable business." (http://www. hep.hr/hep/grupa/profil.aspx, March 2013.) 


\section{LEDO}

Mission and vision (together, $\mathrm{A} / \mathrm{N}$ ): "We are a leading manufacturer of ice cream and frozen food in the region. Employee high expertise and motivation associated with top quality products and sell we build:

- a relationship of favorite and trusted "friend of the entire family" with consumers

- a relationship of serious and reliable partnership with customers

- an image of a dynamic, open and leading company." With the overall environment (http:// www.ledo.hr/hr/o-nama/ledo-danas/misija-i-vizija, March 2013)

\section{BELUPO}

Mission: "Preserve health together."

Vision: "Becoming the leading pharmaceutical company in Central and Eastern Europe." (http://www.belupo.hr/Default.aspx?sid=10484, April 2013)

These examples taken from the sample lead to conclusion that some companies do not recognize the importance of creating vision and mission statements as the base for the later creation of strategy as well as a form of communication with the market. Insufficiently clear mission and vision statements can hardly contribute to the formulation of a clear and effective strategy.

It brings confusion when these statements fail to differentiate the terms "mission" and "vision" or misunderstand other important terms like goals, values, beliefs, strategy. All mentioned above can be examined in the following example where the term "vision" is used to describe the field of activity, and in some way, their mission:

HAC (Hrvatske autoceste, Croatian Highway)

Vision: "The field of activity of Croatian Highway is the highways in the Republic of Croatia, except those which are managed by the concessionaire." (http://www.belupo.hr/Default. aspx?sid=10484, April 2013)

According to these statements taken in consideration, it was very difficult to consolidate the qualitative inputs of these statements in order to have a good starting point of the research and also because "scholars, corporate trainers, and management consultants often emphasize the importance of espousing a vision and even suggest characteristics of an effective vision, no one really knows what such a vision looks like" (Kantabutra and Avery, 2010).

Managers have often developed vision statements unaware of the empirical evidence about constructing an effective vision. Kantabutra and Avery (2010) used the Kantabutra's research from the 2008 which proposes some commonly shared characteristics a vision should have: conciseness; clarity; future orientation; stability; challenge; abstractness; desirability or ability to inspire.

These characteristics were defined for a vision statement, but can be used for mission statement too.

Taking into consideration the 50 successful organizations in Croatia in 2010, their mission and vision statements are rather different and thus was impossible to determine whether they mostly meet the criteria mentioned above, so these characteristics could not be used in this type of research. 
Morphew and Hartley (2006:461) analyzed mission statements and rhetorics in higher education institution, "paid special attention to these elements (words) because of our assumption that this placement at the "top" of the mission statement reflected an organizational emphasis on these particular elements".

According to this methodology, every mission and vision statement was analyzed and divided into "core terms", rated according to the stated importance. In trying to classify the core field of activity presented in the statements, the analysis was made so the order of terms/idioms/ words points is important and describes the activities' priority. Therefore, the first term or grammatical syntagma was given 3 points, the second one 2 , and the third one 1 point. Only the first 3 elements were taken in consideration, because there were rather big differences in statements lengths. Thus the term with the maximum points would be the most important element the organizations have focused on. This analysis was made as in the following example:

\section{JAMNICA}

Mission: "Identifying and meeting the consumers' needs for soft drinks, providing additional value through the ongoing development of our products and services, educating consumers and raising awareness about the drinking culture and the quality and value of natural mineral water, spring water and fruit drinks.

Vision: "Through the continuous investment in existing and new markets, development of products and services and educating employees, consolidating its leading position in the region and becoming a significant player in the global market." (http://www.jamnica.hr/o-nama/misija-ivizija/16-18/?lang=, March 2013)

The order for the mission statement example is:

Consumers' needs- 3 points

Additional value- 2 points

Ongoing product and service development- 1 point

Consumers education- 0 point

Raising awareness- 0 point

The fragmentation of the expression for vision statement has the peculiarity of language inversion because the phrase should be written as "Consolidate its leading position in the region and become a significant player in the global market through continuous investment in existing and new markets, development of products and services, and educating employees." Thus the goals are clearer and the methodology of research is unified for all analyzed statements. The classified terms are:

Consolidate position in the region- 3 points

Significant player in global market- 2 points

Investing in markets- 1 point

Development of products and services- 0 point

Education of employees -0 point

During the statements analysis, it was necessary to pay attention to what is actually the focus of exposed sentence, as it would be easy to classify it as wrong by merely tracing the first term. 
It was sometimes also necessary to interpret the syntagmas in order to avoid the large amount of terms which would bring in no results in the end. Subsequently, the expressions were grouped in clusters according to similar fields of interest, for example syntagma "education of employees" and "investment in employees" belong to group "employees", "the needs of customers" are in group "customer", "ongoing development of product and services" in "product and services", "promoting healthier habits" "society/environment", "be an example of excellence" in "excellence/ improvement" etc.

In total, twelve groups were made, according to statements taken in consideration:

- Additional value

- Business partners

- Business processes

- Customers/consumers

- Employees

- Excellence/improvement/development

- Global market position

- Inland market position

- Innovation

- Organizational culture and quality

- Product and service

- Society/environment

The list and the sum were done in Microsoft Excel.

\section{SEARCH RESULTS AND CONCLUSION}

After the statements analysis and division, applying and summing idiom points, as previously shown, resulted with the most common terms for the mission statements to be:

1. Product and service

2. Customer and consumer

3. Business processes

4. Organizational culture and quality

5. Additional value

These results mirror the present intentions of successful organizations as well as their future steps. The main elements drawn from the mission statements show careful and static view of their present actions. Thus, it is clear that the analyzed organizations exist in order to deliver a good final product or service, to satisfy customers and consumers paying attention to business processes.

It is interesting to see King et al. (2011) findings. They analyzed the mission statements during a 10 year period in U.S., France, Germany, Japan and China. They found out that the customers 
are the most commonly included stakeholders in each of these countries. Customers were included in $64 \%$ of U.S. missions followed by $52 \%$ in Japan, $44 \%$ in Germany and $40 \%$ in both France and China. Employees and community occupy the second and third place but in mission statements of Croatian organizations they are not present among the first five places.

Core elements in vision statements are:

1. Inland market position

2. Excellence/improvement/development

3. Global market position

4. Product and service

5. Organizational culture and quality

The picture of vision statements should show the visionary future that will guide the company towards improvement and expansion. It is very important to notice that the most successful organizations in Croatia lack the primary intention of expanding their business to new markets in times of crisis. Expanding on new markets occupies the third position which is rather disappointing, especially because Croatian market is small and majority of the organizations are parts of the multinational global companies.

Research results indicate that most organizations did not clearly differentiate vision and current company situation, so it questionable whether this vision is set in 10 to 30 year future. This reveals that strategy is formed to satisfy mission goals which are constantly questioned without any innovation and spreading goals.

To sum up, we want to observe a possible strategy created from this kind of mission and vision statements. According to economy situation in times of crisis, it can be defined as a plan pervious to changes, where the organizations must invest in short-term goals, focusing on products and services, customers, business processes and organizational culture. Their efforts must lead to retaining and consolidating of their inland market position, always improving and developing products and services that could be offered on new, global markets.

In some way, returning to the source of strategy in military world, strategy for existing companies is a way to survive, to win a battle, without thinking of a long-term war. 


\section{LIMITATION AND FURTHER RESEARCH}

Hereby presented research must face the following limitations: the difficulty in trying to define the important parts in expressed statements and unification the mission and vision core subjects. The differences in mission and vision expressing prove the organizations in Croatia not yet aware of the statement defining importance as well as their public presentation.

It is also difficult to generally present the situation of formulating a strategy from a vision and mission since the strategy is often kept as a secret of trade. It would be interesting and indicative for this matter to compare the public vision and mission statements with the planned one and finally with the implemented strategy.

Additional research could be applied to reveal the real pictures of these statements or better: research whether the organizations comply with what expressed in their statements. Barkus and Glassman (2008) have concluded that although social issues such as the environment and diversity are less frequently included, their mention in mission statements is significantly associated with behaviors regarding these issues. The inclusion of specific stakeholder groups in mission statement is also likely the result of institutional pressures, while specifying social issues in missions is related to policy decisions.

This conclusion opens further doors of analyzing the relation between mission, vision and consumer's perception; between personal beliefs, leadership styles and creating mission and vision statements, but also the correlation and connection between mission and vision. The frequency of change in statements could be further analyzed in order to determine the way of controlling and monitoring the strategy. In general, the long term aspect of strategy is questioned because of turbulence in present day economy. 


\section{REFERENCES}

Alkhafaji, A., (2003) Strategic Management, Formulation, Implementation and Control in a Dynamic Environment, The Haworth Press, New York

Ansoff, H., I. (1989) Corporate Strategy, Penguin, Harmondsworth

Barkus, B., Glassman, M. (2008), Do Firms Practice What They Preach? The Relationship between Mission Statements and Stakeholder Management, Journal of Business Ethics: 83, 207, 216

Barnett, M. L., (2003) Falling Off the Fence? A Realistic Appraisal of a Real Approach to Corporate Strategy, Journal of Management Inquiry: 12, 185-196

Buble, M. et al., (2005) Strateški menadžment, Sinergija, Zagreb

Chun, R., Davies, G. (2001), E-reputation: The role of mission and vision statements in positioning strategy, Brand management, 8 (4,5), 315-383

Ciavarella, M. A., (2004) The adoption of High-involvement practices and processes in emergent and developing firms: a descriptive and prescriptive approach, Human Resource Management, 42, 337-356

Fox, R., Using Corpus Linguistics to Describe Corporations' Ideologies, Tourism and Hospitality Management, 12 (2), 15-24

Huff, A., Floyd, S., Sherman, H., Terjesen, S., (2009), Strategic Management, Logic and Action, John Wiley and Sons, New York

Kantabutra, S., Avery, G. C. (2010), The Power of vision: statement that resonate, Journal of Businaless Strategy: 31, 37-45

King, D., Case, C., Premo, K., (2012) An International Mission Statement Comparsion: United States, France, Germany, Japan, and China, Academy of Strategic Management Journal 11 (2), 93-119

Lesenciuc, A., Nagy, D. (2008), Role of communication in crisis management, Defense Resources Management in the $21^{\text {st }}$ Century, available on http://conference.dresmara.ro/conferences/2008/10_Lesenciuc_Adrian.pdf

Lynch, R., (2006) Corporate strategy, Fourth edition, Prentice Hall, Engleska

McCabe, S., (2010), Corporate Strategy in construction. Understanding today's theory and practice, Wiley- Blackwell, Oxford

Morphew, Ch, Hartley, M. (2006), Mission Statements: A Thematic Analysis

Nonaka, I., (1991) The knowledge-creating company, Harvard Business review: 6, 96-104

of Rhetoric Across Institutional Type, The Journal of Higher Education, 77 (3), 456-471

Ohmae, K. (1983), The mind of the Strategist, Penguin, Harmondsworth

Porter, M. (1985), Competitive Advantage: crafting and sustaining superior performance, The Free Press, New York

Porter, M.A. (2008), The five Competitive Forces that Shape Strategy, Harvard Business Review: 1, $79-93$ 
Reid, R.D., Sanders, N.R. (2006), Operations Management: An Integrated Approach, Drugo izdanje, Wiley

Roos, J. \& Victor, B. (1999) Towards a new model of strategy-making as serious play, European Management Journal: 17, 348-55

Sandler, Ph., Craig, J. (2003) Strategic management, second edition, MBA Masterclass series, London

Shrivastava, P. Mitroff, I.I. Miller, D., Miglani, A. (1988) Understanding industrial crises, Journal of Management Studies, 4, 285-304

Stemler, S., Bebell, D., (1999), An Empirical Approach to Understanding and Analyzing the Mission Statements of Selected Educational Institutions, New England Educational Research Organization, 1-36

Teerce, D. J., (2010) Alfred Chandler and "capabilities" teory of strategy and management, Industriam and Corporate Change: 19, 297-316

Verna, (2010), The mission statement is a strategic tool: when used properly, Management Decision, $40(5), 448-455$

Verna, H., (2010), Mission Statements- a Study of Intent and Influence, Journal of Services Research, $9(2), 153-172$

Zan, L., (1990) Looking For Theories in Strategy Studies, Scandinavian Journal of Management: 6, 89-108 